\title{
Drought Characterization using Standardized Precipitation Index for Ajmer, Rajasthan, India
}

\author{
Aradhana Thakur ${ }^{1}$, Liansangpuii ${ }^{1}$, Saket Choudhary ${ }^{1}$, Poonam $^{2}$ and Aparajita Singh ${ }^{1}$ \\ ${ }^{1}$ Department of Farm Engg., IAS, Banaras Hindu University, Varanasi, U.P. , 221005, India \\ ${ }^{2}$ Department of Watershed Development and Soil Conservation, Lakshmangarh, Sikar, \\ Rajasthan, India \\ *Corresponding author
}

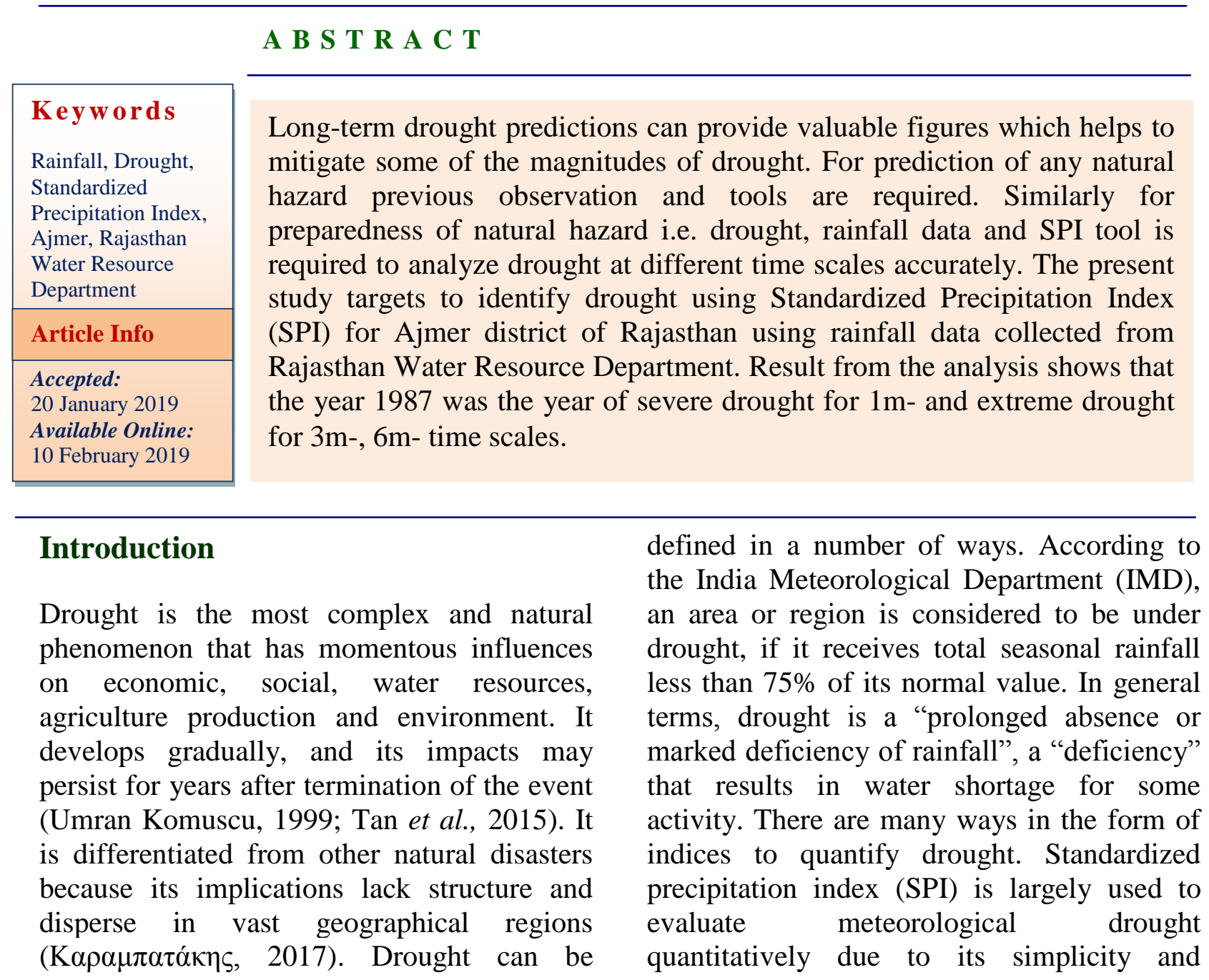


capability of calculating drought at different timescale. But, for precise result long term rainfall data is required (Thakur et al., 2019).

\section{Materials and Methods}

Ajmer a district of Rajasthan in India lies between $25^{\circ} 38^{\prime}$ to $26^{\circ} 58^{\prime} \mathrm{N}$ latitude and $73^{\circ} 54^{\prime}$ to $75^{\circ} 22^{\prime} \mathrm{E}$ longitude (Fig. 1). It is positioned more or less in the mid of Rajasthan. Ajmer is covered with the Nagaur district to the north, the Jaipur and Tonk districts to the east, the Bhilwara district to the south, and the Pali district to the west. To the north of Ajmer city is a large artificial lake called Anasagar, which is decorated with a marble structure called Baradari. The Ajmer District has an area of $8,481 \mathrm{~km}^{2}$.

\section{Standardized Precipitation Index (SPI)}

The SPI method was introduced by McKee et $a l$, in 1993 in University of Colorado. This effort was accomplished by quantifying the rainfall deficit at multiple time scales. More specifically, McKee et al., (1993) estimated the SPI for the time scales of 1, 3, 6, 12, 24, and 48 months. Drought at time scales 1-, 3-, and 6-month is relevant for agriculture, 12month for hydrology and 24-month for socioeconomic impact. In addition, the 1month SPI reflects a short-term condition; the 3-month SPI provides a seasonal estimation of precipitation; the 12-month SPI also reflects medium-term trends in precipitation patterns and may provide an annual estimation of water condition. Therefore, this study used the SPI values at 1-, 3- and 6month scales to discover the drought discrepancy (Tan et al., 2015). Therefore, this multi-temporal approach of SPI provides "a macroscopic insight of the impacts of drought on the availability of water resources"

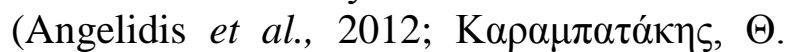
M.2017). The advantage of SPI is, it needed only precipitation data and can be used for both dry and rainy seasons while some indices using specific data as per designed. It can describe drought conditions that are important for a range of meteorological, agricultural, and hydrological applications. Studies have shown that the SPI is suitable for quantifying most types of drought events (Guenang and Kamga, 2014).

The computation of standardized precipitation index consists of following steps:

(1) Calculation of the mean for the normalized precipitation values of the lognormal $\left(\mathrm{L}_{\mathrm{n}}\right)$ rainfall series and computation of the shape and scale parameters $\beta$ and $\alpha$ respectively by the equation given here under,

Log mean

$$
\overline{X_{\mathrm{ln}}}=\frac{\sum \ln X}{N} \ldots
$$

Shape parameter

$$
\beta=\frac{1}{4 U}\left[1+\sqrt{\frac{4 U}{3}}\right]
$$

Scale parameter $\quad \alpha=\frac{\bar{X}}{\beta}$

Here, $\mathrm{U}$ is the constant $U=\ln (\bar{X})-\overline{X_{\mathrm{ln}}}$

(2) The resulting parameters are then used to find the cumulative probability of an observed precipitation event for the given month and time scale for the station in equation. The cumulative probability as given by gamma distribution is as follows:

$G(x)=\frac{1}{\alpha^{\beta} \Gamma \beta} \int_{0}^{x} x^{\beta-1} e^{\frac{-x}{\alpha}} d x$

Letting $t=\frac{-x}{\alpha}$, this equation becomes the incomplete gamma function; 
$G(x)=\frac{1}{\Gamma \beta} \int_{0}^{t \alpha} t^{\beta-1} e^{-t} d t \quad \ldots(\mathrm{v})$

Since the gamma function is undefined for $\mathrm{x}$ $=0$ and a precipitation distribution may contain zero, the cumulative probability becomes

$H(x)=q+(1-q) G(x)$

Where, $\mathrm{q}$ is the probability of a zero.

Thom (1966) states that q can be estimated by $\mathrm{m} / \mathrm{N}$ where $\mathrm{m}$ is the number of zero in a precipitation time series. He used the table of the incomplete gamma function to determine the cumulative probability $\mathrm{G}(\mathrm{x})$. McKee et al., (1993) used an analytic method to determine the cumulative probability.

The cumulative probability $\mathrm{H}(\mathrm{x})$ is then transformed to the standard normal random variable $\mathrm{Z}$ with mean zero and variance one, which is the value of the SPI.

The $\mathrm{Z}$ or SPI value can be easily obtained computationally using an approximation provided by Abramowitz and Stegun (1965) that convert cumulative probability to the standard normal random variable $\mathrm{Z}$.

$$
\begin{aligned}
& \mathrm{Z} \quad \text { SPI } \\
& -\left[t-\frac{c_{0}+c_{1} t+c_{2} t^{2}}{1+d_{1} t+d_{2} t^{2} d_{3} t^{3}}\right] \text { for } 0<H(x) \leq 0.5 \\
& \ldots \text { (vi) } \quad= \\
& \mathrm{Z} \quad \text { SPI } \\
& +\left[t-\frac{c_{0}+c_{1} t+c_{2} t^{2}}{1+d_{1} t+d_{2} t^{2} d_{3} t^{3}}\right] \text { for } 0.5<H(x) \leq 1.0
\end{aligned}
$$

Where,

$\mathrm{t}=\sqrt{\ln \left\{\frac{1}{(H(x))^{2}}\right\}}$ for $0<H(x) \leq 0.5$

(viii) $\mathrm{t}=\sqrt{\ln \left\{\frac{1}{(1-H(x))^{2}}\right\}}$ for $0.5<H(x) \leq 1.0$ ... (ix)

$\mathrm{c}_{0}=2.515517, \mathrm{c}_{1}=0.802853$ and $\mathrm{c}_{2}=$ 0.010328

$\mathrm{d}_{1}=1.432788, \mathrm{~d}_{2}=0.189269$ and $\mathrm{d}_{3}=$ 0.001308

Negative value of SPI shows the drought occurrence anytime until it becomes positive. In order to evaluate the drought severity in different areas using SPI, one of the most commonly used classifications presented by (Hayes et al., 1999) is given in table 1.

\section{Results and Discussion}

The analysis shows the drought severity at 1 , 3 and 6 month time scale for Ajmer district of Rajasthan, India. For the present study the last month of Indian summer monsoon i.e. September month was selected for calculating SPI for above monthly time as negative SPI values in the wet season will indicate drought throughout the year (Palchaudhuri and Biswas, 2013).

\section{$1 \mathrm{~m}$ SPI}

$1 \mathrm{~m}$ SPI results shown in figure 2 reveals that for the study area 23 years were normal years that means the rainfall received during these years did not deviate much from normal annual rainfall. Over the study period both moderate dry and severe dry conditions occurred two times while moderate wet and very wet both conditions happens two times with maximum positive SPI value of 1.96 in 2006. For severe dry conditions the maximum value was -1.92 for the year 1987 .

\section{3m SPI}

Figure 3 shows $3 \mathrm{~m}$ SPI value from for the studied period of 31 years. The result shows 
that 21 years comes under normal category whereas 2 years i.e. 1987 and 2003 were under extremely dry condition.

Two years which are 1993 and 2009 were affected by moderate drought. Six years i.e. 1996, 1997, 2010, 2011, 2012 and 2014 were under moderate wet condition according to classification with SPI value ranging from 1.01 to 1.33 .

\section{6m SPI}

As per $6 \mathrm{~m}$ SPI two years were affected by extreme drought and one year was affected by moderate drought. The years 1996 and 1997 were under very wet condition although 2011 and 2012 were under moderate wet condition. For the study period of 31 years $6 \mathrm{~m}$ SPI value as shown in figure 4 , shows that 24 years had normal precipitation.

Table.1 Standard ranges of SPI values and their classification

\begin{tabular}{|c|c|c|}
\hline S. No. & SPI & Classification \\
\hline 1. & $\geq 2.0$ & Extremely wet \\
\hline 2. & 1.5 to 1.99 & Very wet \\
\hline 3. & 1.0 to 1.49 & Moderately wet \\
\hline 4. & -0.99 to 0.99 & Near normal \\
\hline 7. & -1.0 to -1.49 & Moderate dry \\
\hline 8. & -1.5 to -1.99 & Severe dry \\
\hline 9. & $\leq-2.0$ & Extreme dry \\
\hline
\end{tabular}

Fig.1

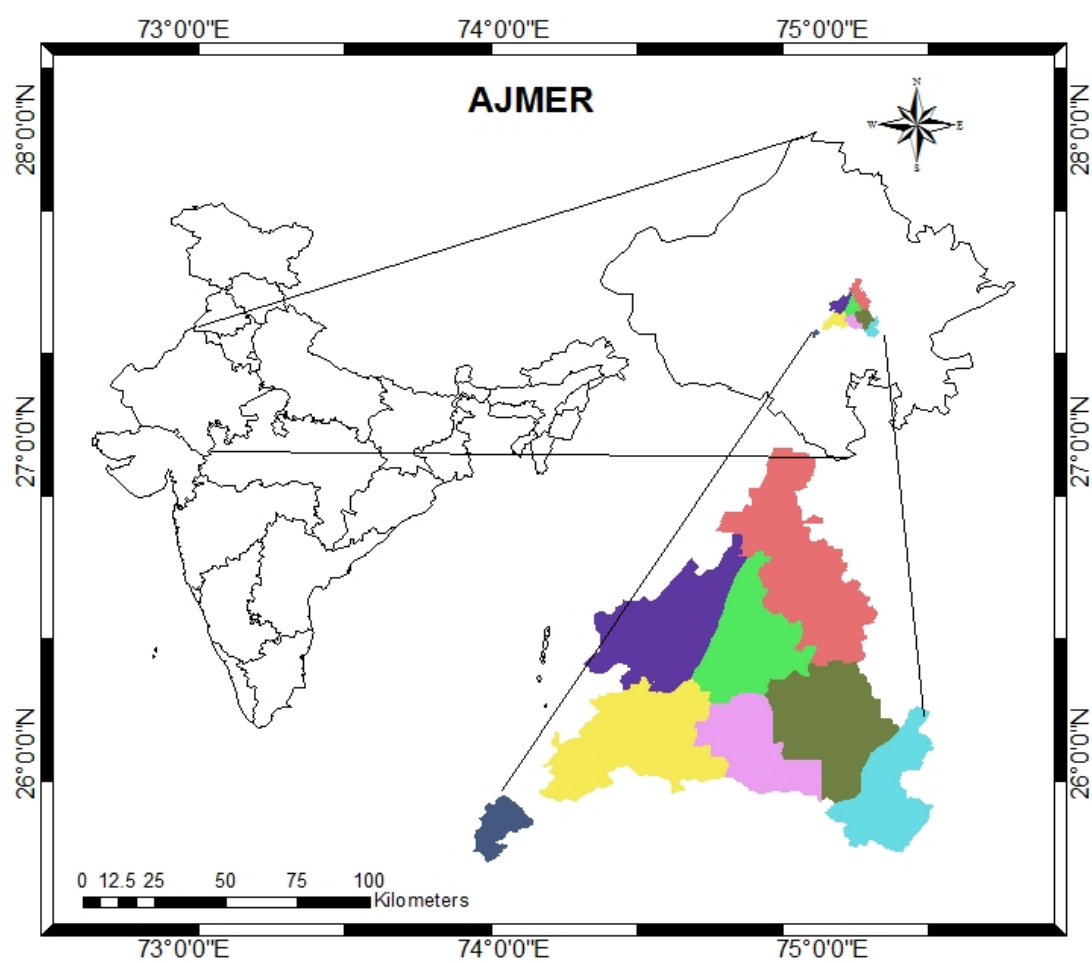


Fig.2

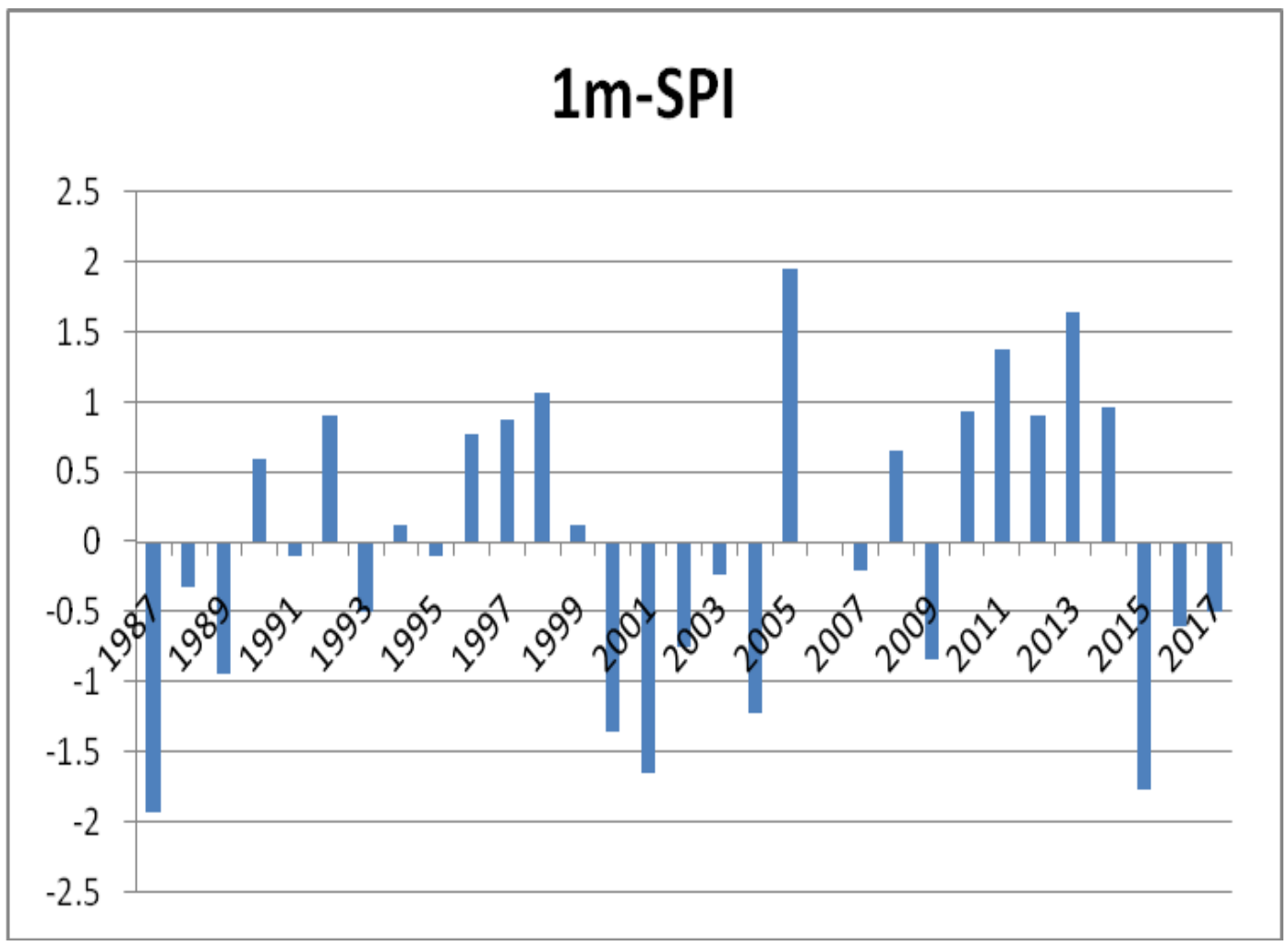

Fig.3

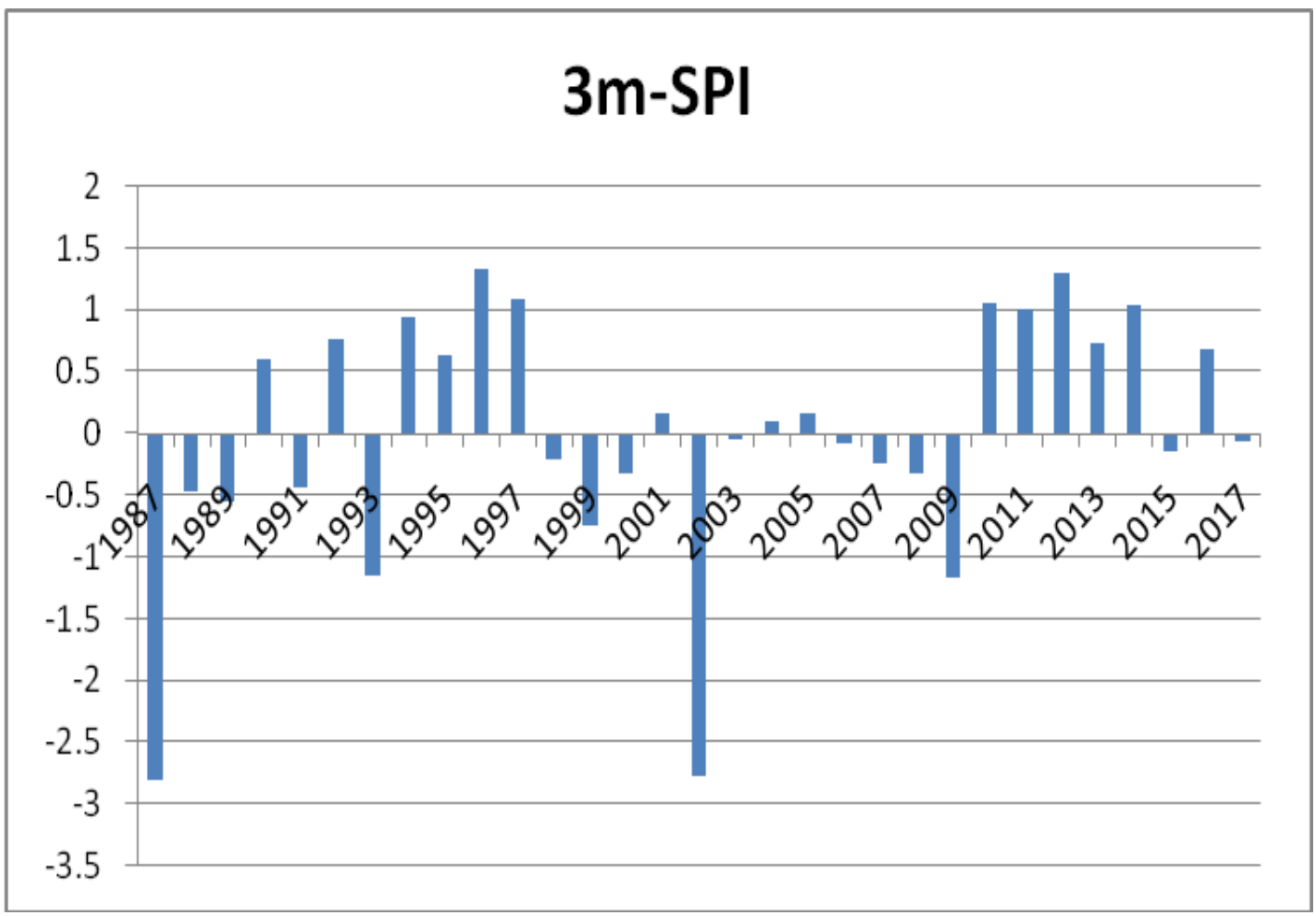


Fig.4

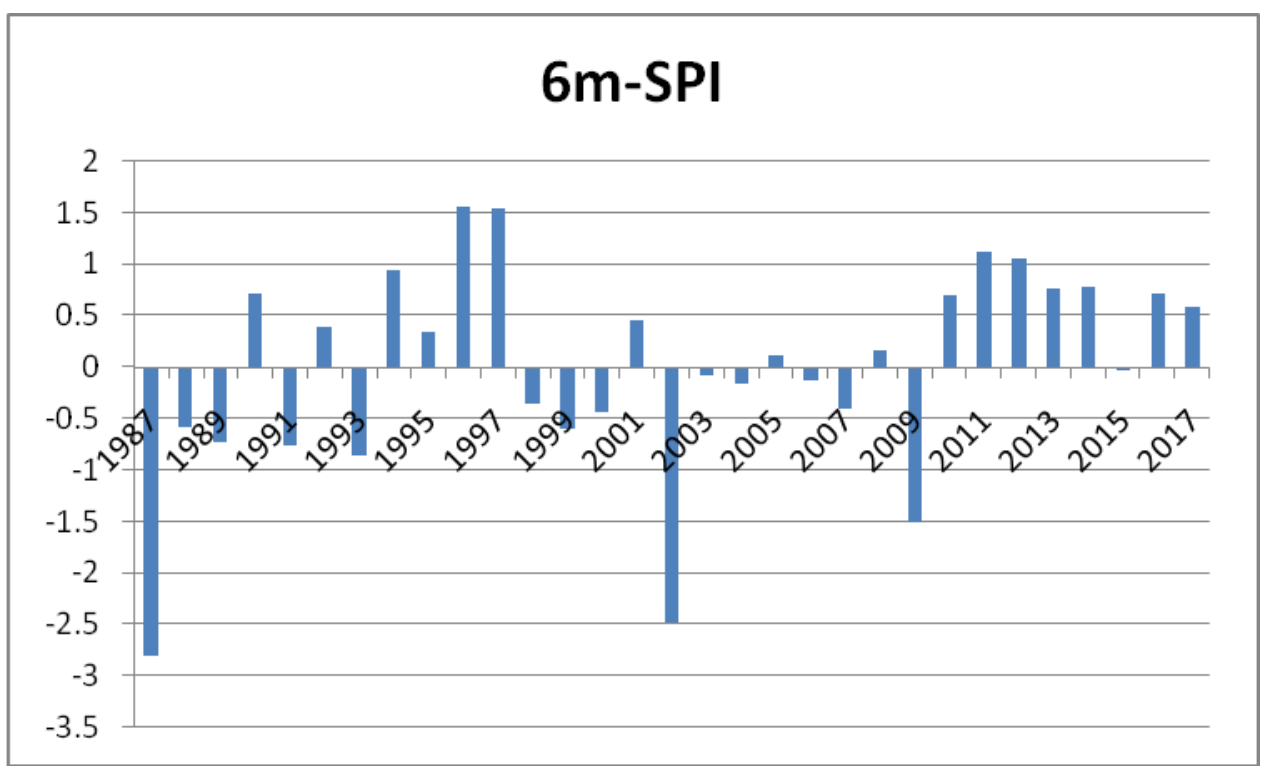

This study concluded that for each time scale more than 21 years have normal rainfall over entire study period while each time scale for the year 1987 shows the occurrence of drought event either severely or extremely. The result of $1 \mathrm{~m}$ SPI shows that there is both wet as well as dry condition occurred while in 23 there were normal years. The results of $3 \mathrm{~m}$ SPI expressed the more number of moderate wet spell years while only two years were extremely dry years over the study period. $6 \mathrm{~m}$ SPI shows all type of spell occurred approximately equal in other than normal years.

\section{References}

Abramowitz, M., and Stegun, I. A. Handbook of mathematical functions: with formulas, graphs, and mathematical tables (1964); (Vol. 55). Courier Corporation.

Angelidis, P., Maris, F., Kotsovinos, N., and Hrissanthou, V. (2012). Computation of drought index SPI with alternative distribution functions. Water resources management, 26(9), 2453-2473.

Guenang, G. M., and Kamga, F. M.
Computation of the standardized precipitation index (SPI) and its use to assess drought occurrences in Cameroon over recent decades. Journal of Applied Meteorology and Climatology (2014); 53(10): 2310-2324. Hayes, M. J., Svoboda, M. D., Wiihite, D. A., and Vanyarkho, O. V. Monitoring the 1996 drought using the standardized precipitation index. Bulletin of the American meteorological society (1999); 80(3): 429-438.

McKee, T. B., Doesken, N. J., and Kleist, J. The relationship of drought frequency and duration to time scales. In Proceedings of the 8th Conference on Applied Climatology (1993); 17(22): 179-183. Boston, MA: American Meteorological Society.

Palchaudhuri, M., and Biswas, S. Analysis of meteorological drought using Standardized Precipitation Index: a case study of Puruliya District, West Bengal, India. International Journal of Environmental Earth Science and Engineering (2013); 7(3): 6-13.

Thakur, A., Liansangpuii, Choudhary, S. \& Poonam. (2019). Temporal analysis of 
drought using standardized precipitation index for Wainganga sub-basin, India. Journal of Pharmacognosy and Phytochemistry, 8(1), 268-272.

UmranKomuscu, A. (1999). Using the SPI to analyze spatial and temporal patterns of drought in Turkey. Drought Network News (1994-2001), 49.


meteorological drought indices, in Thessaly region, Greece (Master's thesis) (2017).

\section{How to cite this article:}

Aradhana Thakur, Liansangpuii, Saket Choudhary, Poonam and Aparajita Singh. 2019. Drought Characterization using Standardized Precipitation Index for Ajmer, Rajasthan, India. Int.J.Curr.Microbiol.App.Sci. 8(02): 2726-2732. doi: https://doi.org/10.20546/ijcmas.2019.802.319 